\title{
Dimensi Partisi Graf Hasil Amalgamasi Siklus
}

\author{
Ahmad Syukur Daming $^{1^{*}}$, Hasmawati Hasmawati $^{2^{*}}$, Loeky Haryanto ${ }^{3 *}$ \\ Budi Nurwahyu ${ }^{*}$
}

\begin{abstract}
Let be a connected graph $\mathrm{G}$ and k-partition $\Pi=\left\{\mathrm{S}_{1}, \mathrm{~S}_{2}, \ldots, \mathrm{S}_{\mathrm{k}}\right\}$ of $\mathrm{V}(\mathrm{G})$ end $v \in V(G)$. The coordinat $v$ to $\Pi$ is definition $r(v \mid \Pi)=\left(d\left(v, S_{1}\right), d\left(v, S_{2}\right), \ldots, d\left(v, S_{k}\right)\right)$. If $r(u \mid \Pi) \neq r(v \mid \Pi)$ for every two vertices in $\mathrm{V}(\mathrm{G})$, then $\Pi$ is a called k-resolving partition of $V(G)$. The minimum $k$ such that $\Pi$ is a k-resolving partition of $V(G)$ is the partition dimension of $G$ and denoted by $p d(\mathrm{G})$. In this paper, we show that the partition dimension for amlagamation of cycle graph $\operatorname{pd}\left(\operatorname{Amal}\left(C_{n}\right)_{m}\right)=3$ for $m=2,3$ and $n \geq 3$. To proof this results, we was used mathematical induction method.
\end{abstract}

Keywords: Partition Dimention, Amalgamation, Cycle Graph

\begin{abstract}
Abstrak
Misalkan terdapat sebuah graf terhubung $G$ dan himpunan partisi $\Pi=\left\{S_{1}, S_{2}, \ldots, S_{k}\right\}$ dari $V(G)$ dan $\quad v \in V(G)$. Koordinat $v$ terhadap $\Pi$ didefinisikan sebagai $r(v \mid \Pi)=\left(d\left(v, S_{1}\right), d\left(v, S_{2}\right), \ldots, d\left(v, S_{k}\right)\right)$. Jika $r(u \mid \Pi) \neq r(v \mid \Pi)$, untuk setiap dua titik berbeda $u, v \in V(G)$, maka $\Pi$ disebut $k$-partisi pembeda dari $V(G)$. Nilai minimum $k$ sehingga $\Pi$ merupakan $k$-partisi pembeda dari $V(G)$ adalah dimensi partisi dari $G$ yang dinotasikan dengan $p d(G)$. Dalam makalah ini ditunjukkan bahwa dimensi partisi dari amalgamasi graf siklus, $p d\left(\operatorname{Amal}\left(C_{n}\right)_{m}\right)=3$ untuk $m=2,3$ dan $n \geq 3$. Metode yang digunakan dalam mengbuktikan hasil tersebut adalah induksi matematika.
\end{abstract}

Kata kunci: Dimensi Partisi, Amalgamasi, Graf Siklus.

\section{Pendahuluan}

Graf adalah pasangan himpunan terurut $(V, E)$, dan ditulis dengan notasi $G=$ $(V, E)$, dengan $V$ adalah himpunan tidak kosong yang anggotanya disebut titik dan $E$ adalah himpunan pasangan-pasangan tidak terurut dari anggota $V$ yang disebut sisi. Salah satu kajian dalam teori graf yang mendapat perhatian dari beberapa peneliti adalah dimensi partisi (partition dimension). Dimensi partisi pertama kali diperkenalkan oleh Chartrand dkk [4]. Mereka mengelompokkan semua titik di $G$ ke dalam sejumlah kelas partisi dan menentukan jarak setiap titik terhadap setiap kelas partisi tersebut.

Terdapat beberapa hasil tentang dimensi partisi suatu graf yang telah diperoleh diantaranya dalam [5] dituliskan bahwa $p d(G)=2$ jika dan hanya jika $G$ adalah graf lintasan $P_{n}$ dan menunjukkan bahwa graf $G$ mempunyai $p d(G)=n$ jika dan hanya jika

*Program Studi Pascasarjana (S2) Matematika, FMIPA-UNHAS

Email : 'ahmadsyukurd@gmail.com, ${ }^{2}$ hasmaba97@gmail.com,

${ }^{3}$ l.haryanto@unhas.ac.id, ${ }^{4}$ budinurwahyu@unhas.ac.id 


\section{Ahmad Syukur Daming, Hasmawati Hasmawati, Loeky Haryanto}

\section{Budi Nurwahyu}

$G$ adalah graf lengkap $K_{n}$. Dalam makalah [9], disajikan batas atas dan bawah dimensi partisi untuk graf pohon. Sedangkan makalah [1], menyajikan dimensi partisi graf amalgamasi bintang. Dimensi partisi graf amalgamasi bintang dan lintasan disajikan dalam makalah [2], sedangkan makalah [6], membahas dimensi partisi untuk graf persahabatan. Dalam makalah ini dibahas penentuan dimensi partisi untuk graf amalgamasi siklus. Beberapa metode yang disajikan pada makalah [2] dan [5] akan dikembangkan untuk digunakan dalam penentuan dimensi partisi graf Amalgamasi siklus. Hasil yang diperoleh dalam penelitian ini, ditulis dalam bentuk lema dan proposisi, dan di akhir buktinya diberi tanda

\section{Tinjauan Pustaka}

Graf $G$ adalah pasangan himpunan $(V(G), E(G))$, dimana $V(G)$ adalah himpunan berhingga tak kosong yang anggota-anggotanya disebut titik, dan $E(G)$ adalah sebuah himpunan (mungkin kosong) dari pasangan-pasangan titik yang disebut sisi. Misalkan sisi $e=\{u, v\} \in E(G)$, maka dikatakan bahwa sisi $e$ terkait dengan titik $u$ dan titik $v$, sedangka titik $u$ dan titik $v$ disebut titik-titik yang bertetangga. Untuk kepentingan penghematan dalam penulisan selanjutnya, sisi $e=\{u, v\} \in E(G)$ hanya ditulis $u v$. Graf $G$ disebut graf terhubung (connected), jika untuk setiap dua titik yang berbeda $u$ dan $v$ di $G$ terdapat suatu lintasan dari $u$ ke $v$ [3]. Panjang suatu lintasan adalah banyaknya sisi yang ada pada lintasan tersebut.

Misalkan $G$ adalah graf sederhana dan $u, v \in V(G)$. Jarak antara titik $u$ dan $v$ dinotasikan dengan $d(u, v)$ adalah

$$
=\left\{\begin{array}{cl}
d(u, v) & \text { dengan } k \text { adalah panjang lintasan terpendek antara } u \text { dan } v \\
0, & u=v \\
\infty, & \text { jika tidak ada kaitan antara } u \text { dan } v .
\end{array}\right.
$$

Dalam maalah [8] disebutkan bahwa graf lintasan $P=(V, E)$ adalah graf dengan himpunan titik $V=\left\{v_{1}, v_{2}, v_{3}, \ldots, v_{n}\right\}$ dan himpunan sisi $E=\left\{v_{1} v_{2}, v_{2} v_{3}, \ldots, v_{n-1} v_{n}\right\}$, dengan setiap $v_{i} \neq v_{j}$ untuk $i=1,2, \ldots, n$. Graf lintasan yang berorder $n$ dinotasikan dengan $P_{n}$ dengan $n \geq 1$. Jika $P_{n}:=v_{1}, v_{2}, \ldots, v_{n}$ adalah suatu graf lintasan berorde $n$ dan $n \geq 3$, maka graf siklus $C_{n}$ adalah graf dengan himpunan titik $\mathrm{V}\left(C_{n}\right)=\mathrm{V}\left(P_{n}\right)$ dan himpunan sisi $\mathrm{E}\left(C_{n}\right)=\mathrm{E}\left(P_{n}\right) \cup\left\{v_{1} v_{n}\right\}$. Graf siklus $C_{n}$ memiliki $n$ titik dan $n$ sisi dengan setiap titiknya berderajat dua.

Misalkan $\left\{G_{i} \mid i \in\{1,2,3, \ldots, m\}\right\}$ untuk $m \in \mathbb{N}$ dan $m \geq 2$, merupakan kumpulan graf berhingga dan masing-masing $G_{i}$ memiliki titik tetap $v_{0 i}$ yang disebut terminal. Amalgamasi $\operatorname{Amal}\left(G_{i}, v_{0 i}\right)$ adalah graf yang dibentuk dengan mengambil semua $G_{i}$ dan menyatukan terminalnya [9]. Graf yang akan di diteliti dalam penelitian ini adalah $\operatorname{Amal}\left(C_{n_{i}}\right)$ dengan $n_{i}=n_{j}>3$ untuk setiap $i, j$ dan $1 \leq i, \mathrm{j} \leq m, m \in N$. Untuk penyederhanaan penulisan dalam penelitian ini $\operatorname{Amal}\left(C_{n_{i}}\right)$ dinotasikan dengan $\operatorname{Amal}\left(C_{n}\right)_{m}$. Himpunan titik $V\left(\operatorname{Amal}\left(C_{n}\right)_{m}\right)=\left\{c, x_{i, j} \mid 1 \leq i \leq n-1,1 \leq j \leq m\right\}$ dan himpuan sisi $E\left(\operatorname{Amal}\left(C_{n}\right)_{m}\right)=\left\{c x_{1, j}, c x_{n-1, j} \mid 1 \leq j \leq 2\right\} \cup\left\{x_{i, j} x_{i+1, j} \mid 1 \leq i \leq n-\right.$ $1,1 \leq j \leq m\}$.

Misalkan terdapat sebuah graf terhubung $G$ dengan $V(G)$ adalah himpunan titiktitiknya, $S \subseteq V(G)$ dan $v \in V(G)$, jarak antara $v$ dengan $S$ yang dinotasikan $d(v, S)$, didefinisikan sebagai $d(v, S)=\min \{d(v, x) \mid x \in S\}$. Misalkan terdapat sebuah graf 


\section{Ahmad Syukur Daming, Hasmawati Hasmawati, Loeky Haryanto}

\section{Budi Nurwahyu}

terhubung $G$ dan koleksi himpunan $\Pi=\left\{S_{1}, S_{2}, \ldots, S_{k}\right\}$, dengan $S_{j}$ adalah partisi dari $V(G)$. Himpunan $\Pi=\left\{S_{1}, S_{2}, \ldots, S_{k}\right\}$ disebut himpunan partisi dan $S_{j}$ disebut kelas partisi. Misalkan $v \in V(G)$. Koordinat $v$ terhadap $\Pi$ didefinisikan sebagai $r(v \mid \Pi)=$ $\left(d\left(v, S_{1}\right), d\left(v, S_{2}\right), \ldots, d\left(v, S_{k}\right)\right)$.

Himpunan partisi $\Pi$ dikatakan $k$-partisi pembeda (resolving partition) jika $k$ vektor $r(v \mid \Pi)$ untuk setiap $v \in V(G)$, berbeda. Nilai minimum $k$ agar terdapat $k$-partisi pembeda dari $V(G)$ adalah dimensi partisi dari $G$, dinotasikan dengan $p d(G)$ [5]. Dalam [6], ditunjukkan bahwa $\operatorname{pd}\left(\operatorname{Amal}\left(C_{n}\right)_{m}\right)=\left\{\begin{array}{l}3, \text { jika } m=2,3 ; \\ 4, \text { jika } m=4,4,6 \text {. }\end{array}\right.$

Dalam penentuan dimensi partisi untuk graf $\operatorname{Amal}\left(C_{n}\right)_{m}$ diperlukan beberapa sifat seperti yang disajikan pada definisi, lema, dan proposisi berikut.

Definisi 2.1. Diberikan suatu graf terhubung $G$ dan $u, v \in V(G)$. Titik $u$ dan $v$ disebut titik-titik yang setara dalam graf $G$ apabila memenuhi salah satu sifat berikut:

a. $d(u, w)=d(v, w)$ untuk setiap $w \in V(G) /\{u, v\}$

b. Untuk setiap $s \in V(G) /\{u, v\}$, terdapat titik $c$ sehingga $d(u, c)+d(c, s)=$ $d(v, c)+d(c, s)$.

Lema 2.1. Diberikan suatu graf terhubung $G$ dengan partisi pembeda $\Pi$ dari $V(G)$, untuk $u, v \in V(G)$. Jika $d(u, w)=d(v, w)$ untuk setiap $w \in V(G) /\{u, v\}$, maka $u$ dan $v$ merupakan unsur yang berada pada kelas partisi yang berbeda di $\Pi$.

Lema 2.2. Diberikan suatu graf terhubung $G$ dan $u, v \in V(G)$ merupakan titik-titik yang setara. Misalkan pula $r \in N(u), s \in N(v)$ dan $\Pi=\left\{S_{1}, \ldots, S_{k}\right\}$ merupakan partisi pembeda dari $G$. Jika $u, v \in S_{i}$, maka $r$ dan $s$ merupakan unsur yang berada pada kelas partisi yang berbeda di $\Pi$.

\section{Bukti.}

Misalkan $\Pi=\left\{S_{1}, \ldots, S_{k}\right\}, u, v \in S_{i}$. Karena $u$ dan $v$ adalah titik-titk yang setara, maka $d(u, w)=d(v, w)$ untuk setiap $w \in V(G) /\{u, v\}$ atau untuk setiap $s \in V(G) /\{u, v\}$, terdapat titik $c$ sehingga $d(u, c)+d(c, s)=d(v, c)+d(c, s)$. Mengingat $\Pi=$ $\left\{S_{1}, \ldots, S_{k}\right\}$ adalah partisi pembeda, $d(u, r)=d(v, s)=1$ dan $d\left(u, S_{i}\right)=d\left(v, S_{i}\right)$ dengan $S_{i} /\{s, r\}$, untuk $r \in N(u)$ dan $s \in N(v)$, maka mestilah terdapat $k, j \in$ $\{1,2, \ldots, k\}$ sehingga $s \in S_{k}$ dan $r \in S_{j}$. Dalam hal ini, $d\left(u, S_{k}\right)=1 \neq d\left(v, S_{k}\right)$ dan $d\left(v, S_{j}\right)=1 \neq d\left(u, S_{j}\right)$.

Teorema 2.1. Diberikan $G$ graf terhubung dengan order $n \geq 2$, maka $p d(G)=2$ jika dan hanya jika $G=P_{n}$. 


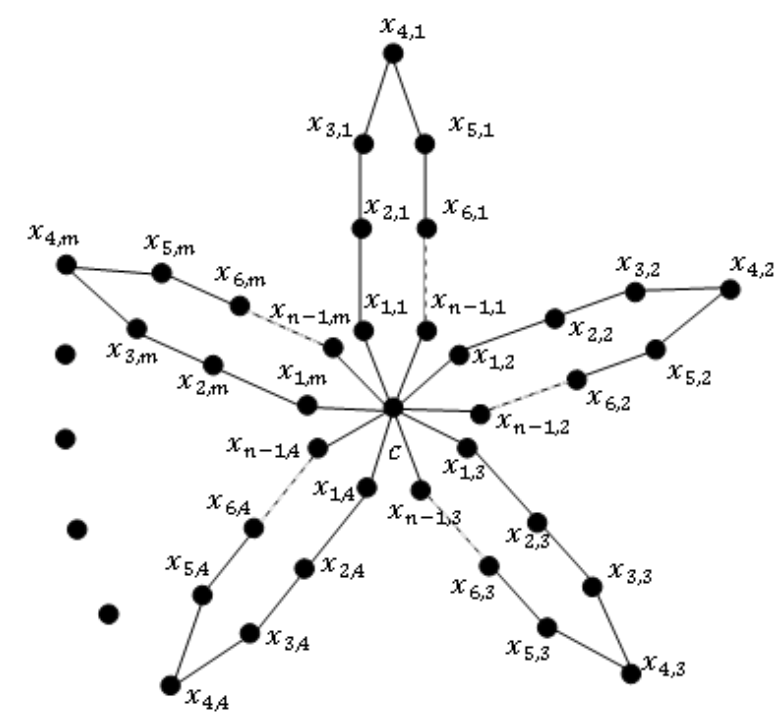

Gambar 1. Graf Hasil Amalgamasi Siklus $\left(\operatorname{Amal}\left(C_{n}\right)_{m}\right)$

\subsection{Dimensi Partisi $\operatorname{Amal}\left(C_{n}\right)_{2}, n \geq 4$.}

Batas atas dimensi partisi $\operatorname{Amal}\left(C_{n}\right)_{2}$ dapat diperoleh dengan mengkonstruksi partisi pembeda $\Pi$ pada graf $\operatorname{Amal}\left(C_{n}\right)_{2}$.

a. Misalkan $n=4$ dengan himpunan titik $V\left(\operatorname{Amal}\left(C_{4}\right)_{2}\right)$ dan himpunan sisi $E\left(\operatorname{Amal}\left(C_{4}\right)_{2}\right)$. Tulis $V\left(\operatorname{Amal}\left(C_{4}\right)_{2}\right)=\{c\} \cup\left\{x_{1,1}, x_{2,1}, x_{3,1}\right\} \cup\left\{x_{1,2}, x_{2,2}, x_{3,2}\right\}$, dengan $V\left(\left(C_{4}\right)_{1}\right)=\left\{c, x_{1,1}, x_{2,1}, x_{3,1}\right\}$ dan $V\left(\left(C_{4}\right)_{2}\right)=\left\{c, x_{1,2}, x_{2,2}, x_{3,2}\right\}$ dan $E\left(\operatorname{Amal}\left(C_{4}\right)_{2}\right)=\left\{c x_{1,1}, x_{1,1} x_{2,1}, x_{2,1} x_{3,1}, x_{3,1} c\right\} \cup\left\{c x_{1,2}, x_{1,2} x_{2,2}, x_{2,2} x_{3,2}, x_{3,2} c\right\}$. Pilih himpunan partisi $\Pi=\left\{S_{1}, S_{2}, S_{3}\right\}$ dengan $S_{1}=\left\{c, x_{1,1}, x_{2,1}, x_{1,2}\right\}, \quad S_{2}=$ $\left\{x_{3,1}, x_{2,2}\right\}$, dan $S_{3}=\left\{x_{3,2}\right\}$. Representasi setiap titik di $\operatorname{Amal}\left(C_{4}\right)_{2}$ terhadap $\Pi$ adalah sebagai berikut:

$r(c \mid \Pi)=(0,1,1)$

$r\left(x_{1,1} \mid \Pi\right)=(0,2,2)=(0,1+1,1+1)$, jika $1 \leq i \leq\left\lfloor\frac{n}{2}\right\rfloor-1$;

$r\left(x_{2,1} \mid \Pi\right)=(0,1,3)=(0,4-2-1,2+1), 2=\left\lfloor\frac{n}{2}\right\rfloor$;

$\left(r\left(x_{i, 1} \mid \Pi\right)=(0, n-i-1, i+1) ;\right.$ jika $\left.i=\left\lfloor\frac{n}{2}\right\rfloor\right)$

$r\left(x_{1,2} \mid \Pi\right)=(0,1,2)$

$r\left(x_{3,1} \mid \Pi\right)=(1,0,2)$

$r\left(x_{2,2} \mid \Pi\right)=(1,0,1)$

$r\left(x_{3,2} \mid \Pi\right)=(1,1,0)=\left(r\left(x_{n-1,2} \mid \Pi\right)=(1,1,0)\right)$ 
Budi Nurwahyu

Hasil observasi menunjukkan semua titik $\operatorname{Amal}\left(C_{4}\right)_{2}$ mempunyai representasi yang berbeda, sehingga $\Pi$ merupakan partisi pembeda dari $\operatorname{Amal}\left(C_{4}\right)_{2}$ dengan kardinalitas $|\Pi|=3$. Jadi, $p d\left(\operatorname{Amal}\left(C_{4}\right)_{2}\right) \leq 3$.

Untuk batas bawah dari dimensi partisi $\operatorname{Amal}\left(C_{4}\right)_{2}$ dapat merujuk pada Proposisi 2.1 menyatakan bahwa $p d(G)=2$ jika dan hanya jika $G \cong P_{n}$. Graf $\operatorname{Amal}\left(C_{n}\right)_{2} ¥ P_{n}$, maka dapat dipastikan batas bawah dari dimensi partisi graf $\operatorname{Amal}\left(C_{n}\right)_{2}$ adalah $\operatorname{pd}\left(\operatorname{Amal}\left(C_{n}\right)_{2}\right) \geq 3$.

Berdasarkan persamaan (3.1), dan (3.2) diperoleh batas bawah dan atas yaitu $3 \leq p d\left(\operatorname{Amal}\left(C_{n}\right)_{2}\right) \leq 3$. Jadi dimensi partisi graf $\operatorname{Amal}\left(C_{4}\right)_{2}$ adalah $\operatorname{pd}\left(\operatorname{Amal}\left(C_{4}\right)_{2}\right)=3$.

b. Misalkan $n=5$ dengan himpunan titik $V\left(\operatorname{Amal}\left(C_{5}\right)_{2}\right)$ dan himpunan sisi $E\left(\operatorname{Amal}\left(C_{5}\right)_{2}\right)$.

Tulis

$V\left(\operatorname{Amal}\left(C_{5}\right)_{2}\right)=\{c\} \cup\left\{x_{1,1}, x_{2,1}, x_{l, 1}, x_{3,1}\right\} \cup\left\{x_{1,2}, x_{2,2}, x_{l, 2}, x_{3,2}\right\}, \quad$ dengan

$V\left(\left(C_{5}\right)_{1}\right)=\left\{c, x_{1,1}, x_{2,1}, x_{l, 1}, x_{3,1}\right\} \quad$ dan $V\left(\left(C_{5}\right)_{2}\right)=\left\{c, x_{1,2}, x_{2,2}, x_{l, 2}, x_{3,2}\right\}$ dan $E\left(\operatorname{Amal}\left(C_{5}\right)_{2}\right)=\left\{\begin{array}{c}\left\{c x_{1,1}, x_{1,1} x_{2,1}, x_{2,1} x_{l, 1}, x_{l, 1} x_{3,1}, x_{3,1} c\right\} \cup \\ \left\{c x_{1,2}, x_{1,2} x_{2,2}, x_{2,2} x_{l, 2}, x_{l, 2} x_{3,2}, x_{3,2} c\right\}\end{array}\right\}$.

Pilih himpunan partisi $\Pi=\left\{S_{1}^{\prime}, S_{2}^{\prime}, S_{3}^{\prime}\right\}$ dengan $S_{1}^{\prime}=\left\{c, x_{1,1}, x_{2,1}, x_{l, 1}, x_{1,2}\right\}=S_{1} \cup$ $\left\{x_{l, 1}\right\}, \quad S_{2}^{\prime}=\left\{x_{3,1}, x_{2,2}, x_{l, 2}\right\}=S_{2} \cup\left\{x_{l, 2}\right\}, \quad$ dan $S_{3}^{\prime}=\left\{x_{3,2}\right\}=S_{3}$. Refresentasi setiap titik di $\operatorname{Amal}\left(C_{5}\right)_{2}$ terhadap $\Pi$ adalah sebagai berikut:

$r(c \mid \Pi)=(0,1,1)$

$$
\begin{aligned}
& r\left(x_{i, 1} \mid \Pi\right)=(0,2,2)=(0, i+1, i+1) ; \text { jika } 1 \leq i \leq\left\lfloor\frac{5}{2}\right\rfloor-1 \\
& r\left(x_{i, 1} \mid \Pi\right)=(0,2,3)=(0, n-i-1, i+1) ; \text { jika } i=\left\lfloor\frac{5}{2}\right\rfloor \\
& r\left(x_{i, 1} \mid \Pi\right)=(0,1,3)=(0, n-i-1, n-i+1) ; \text { jika }\left\lfloor\frac{5}{2}\right\rfloor+1 \leq i \leq 5-2 \text { untuk } \\
& n \geq 5 \\
& r\left(x_{n-1,1} \mid \Pi\right)=(1,0,2) \\
& r\left(x_{1,2} \mid \Pi\right)=(0,1,2) \\
& r\left(x_{i, 2} \mid \Pi\right)=(1,0,2)=(i-1,0, n-i-1) ; \text { jika } i=\left\lfloor\frac{5}{2}\right\rfloor \\
& r\left(x_{i, 2} \mid \Pi\right)=(2,0,1)=(n-i-1,0, n-i+1) ; \text { jika }\left\lfloor\frac{5}{2}\right\rfloor+1 \leq i \leq 5-2 \text { dan } n \geq 5 \\
& r\left(x_{n-1,2} \mid \Pi\right)=(1,1,0) .
\end{aligned}
$$

Hasil observasi menunjukkan bahwa semua titik $\operatorname{Amal}\left(C_{5}\right)_{2}$ mempunyai representasi yang berbeda, sehingga $\Pi$ merupakan partisi pembeda dari $\operatorname{Amal}\left(C_{5}\right)_{2}$ dengan kardinalitas $|\Pi|=3$. Jadi, $p d\left(\operatorname{Amal}\left(C_{n}\right)_{2}\right) \leq 3$.

Untuk batas bawah dari dimensi partisi $\mathrm{Amal}\left(C_{5}\right)_{3}$ dapat merujuk pada Proposisi 2.1 menyatakan bahwa $p d(G)=2$ jika dan hanya jika $G \cong P_{n}$. $\operatorname{Graf} \operatorname{Amal}\left(C_{n}\right)_{2} ¥ P_{n}$, maka dapat dipastikan batas bawah dari dimensi partisi graf $\operatorname{Amal}\left(C_{5}\right)_{2}$ adalah $\operatorname{pd}\left(\operatorname{Amal}\left(C_{5}\right)_{2}\right) \geq 3$.

Berdasarkan persamaan (3.3) dan (3.4) diperoleh batas bawah dan atas yaitu $3 \leq \operatorname{pd}\left(\operatorname{Amal}\left(C_{n}\right)_{2}\right)=3$. Jadi dimensi partisi graf $\operatorname{Amal}\left(C_{n}\right)_{3}$ adalah $\operatorname{pd}\left(\operatorname{Amal}\left(C_{5}\right)_{2}\right)=3$. 


\section{Budi Nurwahyu}

\subsection{Dimensi partisi $\operatorname{Amal}\left(C_{n}\right)_{3}$}

Penentuan dimensi partisi $\operatorname{Amal}\left(C_{n}\right)_{3}$ dimulai dengan $n=4$.

a. Misalkan $V\left(\operatorname{Amal}\left(C_{4}\right)_{3}\right)=\{c\} \cup\left\{x_{1,1}, x_{2,1}, x_{3,1}\right\} \cup\left\{x_{1,2}, x_{2,2}, x_{3,2}\right\}$

$\bigcup\left\{x_{1,3}, x_{2,3}, x_{3,3}\right\}$ dengan $V\left(\left(C_{4}\right)_{1}\right)=\left\{c, x_{1,1}, x_{2,1}, x_{3,1}\right\}$,

$V\left(\left(C_{4}\right)_{2}\right)=\left\{c, x_{1,2}, x_{2,2}, x_{3,2}\right\}, V\left(\left(C_{4}\right)_{3}\right)=\left\{c, x_{1,3}, x_{2,3}, x_{3,3}\right\}$ dan

$$
E\left(\operatorname{Amal}\left(C_{4}\right)_{3}\right)=\left\{c x_{1, j}, x_{i, j} x_{i+1, j}, x_{3, j} c\right\}, i=1,2 ; j=1,2,3 \text {; }
$$

Pilih himpunan partisi $\Pi=\left\{S_{1}, S_{2}, S_{3}\right\}$ dengan $S_{1}=\left\{c, x_{1,1}, x_{2,1}, x_{1,2}, x_{1,3}\right\}$, $S_{2}=\left\{x_{3,1}, x_{2,2}\right\}$, dan $S_{3}=\left\{x_{3,2}, x_{2,3} x_{3,3}\right\}$. Representasi setiap titik di $\operatorname{Amal}\left(C_{4}\right)_{3}$ terhadap $\Pi$ adalah sebagai berikut:

$$
\begin{gathered}
r(c \mid \Pi)=(0,1,1) \\
r\left(x_{1,1} \mid \Pi\right)=(0,2,2) ;
\end{gathered}
$$

$r\left(x_{2,1} \mid \Pi\right)=(0,1,3)$

$r\left(x_{1,2} \mid \Pi\right)=(0,1,2)$;

$r\left(x_{3,1} \mid \Pi\right)=(1,0,2)$;

$r\left(x_{2,2} \mid \Pi\right)=(1,0,1)$;

$r\left(x_{3,2} \mid \Pi\right)=(1,1,0)$

$$
\begin{aligned}
& r\left(x_{1,3} \mid \Pi\right)=(0,2,1) ; \\
& r\left(x_{2,3} \mid \Pi\right)=(1,3,0) ; \\
& r\left(x_{3,3} \mid \Pi\right)=(1,2,0) .
\end{aligned}
$$

Hasil observasi menunjukkan semua titik $\operatorname{Amal}\left(C_{4}\right)_{3}$ mempunyai representasi yang berbeda terhadap $\Pi$, sehingga $\Pi$ merupakan partisi pembeda dari $\operatorname{Amal}\left(C_{4}\right)_{3}$ dengan kardinalitas $|\Pi|=3$. Jadi, $\operatorname{pd}\left(\operatorname{Amal}\left(C_{4}\right)_{3}\right) \leq 3$. Menurut Proposisi 2.1, $\operatorname{pd}\left(\operatorname{Amal}\left(C_{4}\right)_{3}\right) \geq 3$. Jadi $p d\left(\operatorname{Amal}\left(C_{4}\right)_{3}\right)=3$.

b. Misalkan $V\left(\operatorname{Amal}\left(C_{5}\right)_{3}\right)=\{c\} \cup\left\{x_{1,1}, x_{2,1}, x_{l, 1}, x_{3,1}\right\} \cup\left\{x_{1,2}, x_{2,2}, x_{l, 2}, x_{3,2}\right\}$ $\bigcup\left\{x_{1,3}, x_{2,3}, x_{l, 3}, x_{3,3}\right\} \quad$ dengan $V\left(\left(C_{5}\right)_{1}\right)=\left\{c, x_{1,1}, x_{2,1}, x_{l, 1}, x_{3,1}\right\}, V\left(\left(C_{5}\right)_{2}\right)=$ $\left\{c, x_{1,2}, x_{2,2}, x_{l, 2}, x_{3,2}\right\}, V\left(\left(C_{5}\right)_{3}\right)=\left\{c, x_{1,3}, x_{2,3}, x_{l, 3}, x_{3,3}\right\}$ dan $\left\{c x_{1,1}, x_{1,1} x_{2,1}, x_{2,1} x_{l, 1}, x_{l, 1} x_{3,1}, x_{3,1} c\right\} \cup$

$$
\begin{aligned}
E\left(\operatorname{Amal}\left(C_{5}\right)_{3}\right)= & \left\{c x_{1,2}, x_{1,2} x_{2,2}, x_{2,2} x_{l, 2}, x_{l, 2} x_{3,2}, x_{3,2} c\right\} \cup \\
& \left\{c x_{1,3}, x_{1,3} x_{2,3}, x_{2,3} x_{l, 3}, x_{l, 3} x_{3,3}, x_{3,3} c\right\}
\end{aligned}
$$

Pilih himpunan partisi $\Pi=\left\{S_{1}, S_{2}, S_{3}\right\}$ dengan $S_{1}=\left\{c, x_{1,1}, x_{2,1}, x_{l, 1}, x_{1,2}, x_{1,3}\right\}$, $S_{2}=\left\{x_{3,1} x_{2,2}, x_{l, 2}, x_{3,3}\right\}$, dan $S_{3}=\left\{x_{3,2}, x_{2,3} x_{l, 3}\right\}$. Refresentasi setiap titik di $\operatorname{Amal}\left(C_{5}\right)_{3}$ terhadap $\Pi$ adalah sebagai berikut: 


\section{Ahmad Syukur Daming, Hasmawati Hasmawati, Loeky Haryanto}

\section{Budi Nurwahyu}

Untuk representasi titik $c$ dan $x_{i, j}$ dimana $1 \leq i \leq 3$ dan $1 \leq j \leq 2$ sama dengan representasi titik pada graf $\operatorname{Amal}\left(C_{4}\right)_{2}$, sedangkan titik $x_{l, j}$ dan titik $x_{i, 3}$ untuk $i, j$, $1 \leq i \leq 3$ dan $1 \leq j \leq m$ adalah

$$
\begin{aligned}
& r\left(x_{l, 1} \mid \Pi\right)=(0,1,3)=r\left(x_{(n-2), 1} \mid \Pi\left(\left(C_{n}\right)_{2}\right)\right) ; \\
& r\left(x_{l, 2} \mid \Pi\right)=r\left(x_{(n-2), 1} \mid \Pi\left(\left(C_{n}\right)_{2}\right)\right)=(2,0,1) \\
& r\left(x_{1,3} \mid \Pi\right)=(0,2,1) \\
& r\left(x_{i, 3} \mid \Pi\right)=(1,2,0)=(i-1, n-i, 0) ; \text { jika } i=\left\lfloor\frac{4}{2}\right\rfloor \\
& r\left(x_{l, 3} \mid \Pi\right)=(2,1,0)=(n-i, n-i+1,0) ; \text { jika }\left\lfloor\frac{4}{2}\right\rfloor+1 \leq i \leq 3 \\
& r\left(x_{n-1,3} \mid \Pi\right)=(1,2,0) .
\end{aligned}
$$

Hasil observasi menunjukkan semua titik $\operatorname{Amal}\left(C_{5}\right)_{3}$ mempunyai representasi yang berbeda, sehingga $\Pi$ merupakan partisi pembeda dari $\operatorname{Amal}\left(C_{5}\right)_{3}$ dengan kardinalitas $|\Pi|=3$. Jadi, $p d\left(\operatorname{Amal}\left(C_{5}\right)_{3}\right) \leq 3$. Serupa dengan batas bawah $\operatorname{Amal}\left(C_{4}\right)_{3}$ bahwa menurut Proposisi 2.1, diperoleh $\operatorname{pd}\left(\operatorname{Amal}\left(C_{5}\right)_{3}\right) \geq 3$. Jadi $p d\left(\operatorname{Amal}(5)_{3}\right)=3$.

Dengan cara yang serupa dapat ditunjukkan bahwa $\operatorname{pd}\left(\operatorname{Amal}\left(C_{n}\right)_{2}\right)$ dan $\operatorname{pd}\left(\operatorname{Amal}\left(C_{n}\right)_{3}\right)$ adalah 3 untuk $n=6$ dan $n=7$. Graf $\operatorname{Amal}\left(C_{7}\right)_{2}$ dan $\operatorname{Amal}\left(C_{7}\right)_{3}$ dapat dilihat pada Gambar 2.

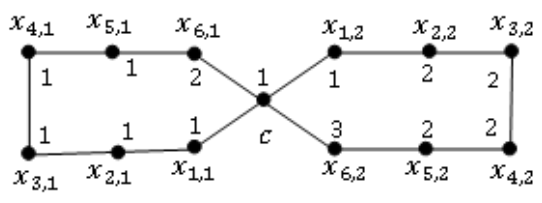

(a)

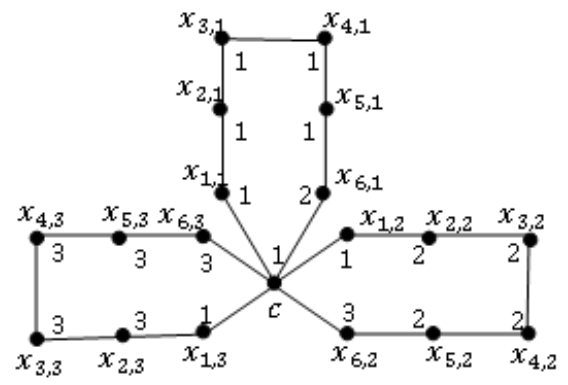

(b)

Gambar 2. Partisi Pembeda (a) $\operatorname{Amal}\left(C_{7}\right)_{2}$ dan (b) $\operatorname{Amal}\left(C_{7}\right)_{3}$

Berdasarkan hasil pada Subbab 2.1 dan 2.2, dirumuskan perumuman partisi dimensi graf $\operatorname{Amal}\left(C_{n}\right)_{m}$ untuk $2 \leq m \leq 3$ dalam bentuk teorema seperti berikut.

Proposisi 2.2: Jika $n \geq 4$ dan $2 \leq m \leq 3$, maka $p d\left(\operatorname{Amal}\left(C_{n}\right)_{m}\right)=3$.

Bukti:

Pembuktian Proposisi 2.2 menggunakan metode induksi matematika, yaitu:

1) Berdasarkan hasil pada Subbab 2.1 dan 2.2 diperoleh :

a. Untuk $n=4$ dan $m=2,3, p d\left(\operatorname{Amal}\left(C_{n}\right)_{m}\right)=3$

b. Untuk $n=5$ dan $m=2,3, p d\left(\operatorname{Amal}\left(C_{n}\right)_{m}\right)=3$

c. Untuk $n=6$ dan $m=2,3, p d\left(\operatorname{Amal}\left(C_{n}\right)_{m}\right)=3$

d. Untuk $n=7$ dan $m=2,3, p d\left(\operatorname{Amal}\left(C_{n}\right)_{m}\right)=3$ 


\section{Ahmad Syukur Daming, Hasmawati Hasmawati, Loeky Haryanto}

\section{Budi Nurwahyu}

2) Asumsikan bahwa untuk $2 \leq m \leq 3, \operatorname{pd}\left(\operatorname{Amal}\left(C_{n}\right)_{m}\right)=3$ adalah benar jika $n=l \geq 4$, yaitu $\operatorname{pd}\left(\operatorname{Amal}\left(C_{l}\right)_{m}\right)=3$ dengan partisi pembeda minimum adalah $\Pi=\left\{S_{1}, S_{2}, S_{3}\right\}$

$S_{1}=\left\{c, x_{i, 1}, x_{1,2}, x_{1, m} \mid 1 \leq i \leq n-2\right\}, \quad S_{2}=\left\{x_{n-1,1}, x_{i, 2}, x_{n-1, m} \mid 2 \leq i \leq n-2\right\}$, dan $S_{3}=\left\{x_{n-1,2}, x_{i, m} \mid 2 \leq i \leq n-2\right\}$. Dalam hal ini,

$$
\begin{aligned}
& V\left(\operatorname{Amal}\left(C_{l}\right)_{m}\right)=\{c\} \cup\left\{x_{1,1}, x_{1,2}, \ldots, x_{1, m}\right\} \cup \ldots \cup\left\{x_{l, 1}, \ldots, x_{l, m}\right\} \text { dan } \\
& E\left(\operatorname{Amal}\left(C_{l}\right)_{3}\right)=\left\{c x_{1, j}, x_{1, j} x_{2, j}, x_{2, j} x_{3, j}, \ldots, x_{l-1,1} x_{l, 1}, x_{l, j} c ; j=1,2, \ldots, m\right\} .
\end{aligned}
$$

3) Selanjutnya akan ditunjukkan bahwa proposisi juga benar untuk $n=l+1$, yaitu jika $2 \leq m \leq 3$ maka $p d\left(\operatorname{Amal}\left(C_{l+1}\right)_{m}\right)=3$.

Graf $\operatorname{Amal}\left(C_{l+1}\right)_{m}$ merupakan graf dengan penambahan satu titik sebut $x_{0, j}$ pada sisi $e=x_{n-2, j} x_{n-1, j} \forall j \in[1, m]$ di graf $\operatorname{Amal}\left(C_{n}\right)_{m}$.

Untuk menentukan dimensi partisi $\left.\operatorname{pd}\left(\operatorname{Amal}\left(C_{l+1}\right)_{m}\right)\right)$ dapat diperoleh dengan mengkonstruksi partisi pembeda graf $\operatorname{Amal}\left(C_{l+1}\right)_{m}$. Misalkan $\Pi^{\prime}=\left\{S_{1}^{\prime}, S_{2}^{\prime}, S_{3}^{\prime}\right\}$ sedemikian sehingga :

a. Untuk $m=2$,

$S_{1}^{\prime}=\left\{c, x_{i, 1}, x_{1,2} \mid 1 \leq i \leq n-2\right\} \cup\left\{x_{0,1}\right\}=S_{1} \cup\left\{x_{0,1}\right\}$,

$S_{2}^{\prime}=\left\{x_{n-1,1}, x_{i, 2} \mid 2 \leq i \leq n-2\right\} \cup\left\{x_{0,2}\right\}=S_{2} \cup\left\{x_{0,2}\right\}$, dan

$S_{3}^{\prime}=\left\{x_{n-1,2}\right\}=S_{3}$

Representasi setiap titik di $\operatorname{Amal}\left(C_{l+1}\right)_{2}$ terhadap $\Pi^{\prime}$ adalah sebagai berikut:

$r\left(c \mid \Pi^{\prime}\right)=(0,1,1)$

$r\left(x_{i, 1} \mid \Pi^{\prime}\right)=(0, i+1, i+1) ;$ jika $1 \leq i \leq\left\lfloor\frac{n}{2}\right\rfloor$

$r\left(x_{i, 1} \mid \Pi^{\prime}\right)=(0, n-i, n-i+2)$; jika $\left\lfloor\frac{n}{2}\right\rfloor+1 \leq i \leq n-2$ untuk $n \geq 5$,

karena $x_{n-2, j} \leq x_{0, j} \leq x_{n-1, j}$.

$r\left(x_{1,2} \mid \Pi^{\prime}\right)=(0,1,2)$

$r\left(x_{0,1} \mid \Pi^{\prime}\right)=(0,1,3)$

$r\left(x_{n-1,1} \mid \Pi^{\prime}\right)=(1,0,2)$

$r\left(x_{i, 2} \mid \Pi^{\prime}\right)=(i-1,0, i+1) ;$ jika $2 \leq i \leq\left\lfloor\frac{n}{2}\right\rfloor$

$r\left(x_{i, 2} \mid \Pi^{\prime}\right)=(n-i+1,0, n-i) ;$ jika $\left\lfloor\frac{n}{2}\right\rfloor+1 \leq i \leq n-2$ dan $n \geq 5$

$r\left(x_{0,2} \mid \Pi^{\prime}\right)=(2,0,1)$

$r\left(x_{n-1,2} \mid \Pi^{\prime}\right)=(1,1,0)$

b. Untuk $m=3$, tulis $\Pi^{\prime \prime}=\left\{S_{1}^{\prime \prime}, S_{2}^{\prime \prime}, S_{3}^{\prime \prime}\right\}, S_{1}^{\prime \prime}=S_{1} \cup\left\{x_{0,1}\right\}, S_{2}^{\prime \prime}=S_{2} \cup\left\{x_{n-1, m}, x_{0,2}\right\}$, $\operatorname{dan} S_{3}^{\prime \prime}=\left\{x_{n-1,2}, x_{i, 3} \mid 2 \leq i \leq n-2\right\} \cup\left\{x_{0,3}\right\}=S_{3} \cup\left\{x_{i, 3} \mid 2 \leq i \leq n-2\right\} \cup$ $\left\{x_{0,3}\right\}$

untuk setiap $n \in N$. Karenanya, representasi titik $c$ dan $x_{i, j}$ dimana $1 \leq i \leq n-1$ dan $1 \leq j \leq 2$ sama dengan representasi titik pada graf $\operatorname{Amal}\left(C_{n}\right)_{2} n \in N$.

Sedangkan titik $x_{i, 3}$ dimana $1 \leq i \leq n-1$ dan titik $x_{l, 3}$ adalah sebagai berikut:

$r\left(x_{1,3} \mid \Pi^{\prime \prime}\right)=(0,2,1)$ 


$$
\begin{aligned}
& r\left(x_{i, 3} \mid \Pi^{\prime \prime}\right)=(i-1, i+1,0) ; \text { jika } 2 \leq i \leq\left\lfloor\frac{n}{2}\right\rfloor \\
& r\left(x_{i, 3} \mid \Pi^{\prime \prime}\right)=(i-1, n-i+2,0) ; \text { jika } i=\left\lfloor\frac{n}{2}\right\rfloor+1 \\
& r\left(x_{i, 3} \mid \Pi^{\prime \prime}\right)=(n-i+1, n-i+2,0) ; \text { jika }\left\lfloor\frac{n}{2}\right\rfloor+2 \leq i \leq n-2 \text { dan } n \geq 5 \\
& r\left(x_{0,3} \mid \Pi^{\prime \prime}\right)=(2,3,0) \\
& r\left(x_{n-1,3} \mid \Pi^{\prime \prime}\right)=(1,2,0)
\end{aligned}
$$

Terlihat bahwa representasi setiap titik graf $\operatorname{Amal}\left(C_{n+1}\right)_{m}$, untuk $m=2,3$ terhadap himpunan partisi $\Pi^{\prime \prime}$ adalah berbeda. Dengan demikian himpunan partisi $\Pi^{\prime \prime}$ merupakan partisi pembeda untuk graf $\operatorname{Amal}\left(C_{n+1}\right)_{m}$, dengan $m=2$,3. Jadi $\left|\Pi^{\prime \prime}\right|=|\Pi|=3 \operatorname{pd}\left(\operatorname{Amal}\left(C_{n}\right)_{m}\right) \leq 3$, jika $2 \leq m \leq 3$. Menurut Proposisi 2.1, $\operatorname{pd}\left(\operatorname{Amal}\left(C_{n}\right)_{m}\right) \geq 3$. Jadi $p d\left(\operatorname{Amal}\left(C_{n}\right)_{m}\right)=3$ untuk setiap $n \in N, n \geq 4$ dan $2 \leq m \leq 3$.

\section{Daftar Pustaka}

[1] Asmiati. 2012. Partition Dimension of Amalgamation of Stars. Bulletin of Mathematics. 02(04): 161-167.

[2] Asmiati. 2016. Dimensi Partisi Graf Amalgamasi Bintang yang Dihubungkan Suatu Lintasan. Jurnal Matematika, Fakultas Matematika dan Ilmu Pengetahuan Alam Universitas Lampung. 19(3): 93-95.

[3] Chartrand, G., dan Oellermann, O. R. 1993. Applied and Algorithmic Graph Theory. McGraw-Hill, Inc, New York-St. Louis-San Francisco.

[4] Chartrand, G., Salehi, E., dan Zang, P. 1998. On The Partition Dimension of Graph. Congressus Numerantium. Vol. 130: 157-168.

[5] Chartrand, G., Salehi, E., dan Zang, P. 2000. The Partition Dimension of Graph. Aequationes Mathematicae. 59: 45-54.

[6] Darmaji. 2011. Dimensi Partisi Graf Multipartit dan Graf Hasil Korona Dua Graf Terhubung. Disertasi. Bandung: Institut Teknologi Bandung, Indonesia.

[7] Diestel R. 2005. Graph Theory, Third Edition. Springer-Verlag Heidelberg. New York.

[8] Fitriani, D., Salman, A. N. M. 2016. Rainbow connection number of amalgamation of some graphs. AKCE International journal of graphs and combinatorics. $13: 90$ 99.

[9] Juan, R., Yero, I. G., dan Lemanska, M. 2014. On the Partition Dimension of Trees. Discrete Applied Mathematics. 166: 204-209. 